\title{
Comparing Student Assessed Competencies in PBL and Traditional ECE Programs
}

\author{
P.D. Lawrence, C.A. Hennessey, J. Calviño-Fraga, A. Ivanov, D.L. Pulfrey, S.E. Salcudean, \\ M. Yedlin, M.S. Davies, L. Chrostowski, J. Madden, S. Mirabbasi, K. Walus \\ Department of Electrical and Computer Engineering, University of British Columbia
}

\begin{abstract}
Since 1999, both traditional and project based learning (PBL) programs have been offered to second year ECE students at the University of British Columbia. This paper describes the structure of the PBL program and a student evaluation of their competencies. The evaluation was carried out by a survey of third and fourth year students who passed through either the PBL or the traditional program. Results of the evaluation indicate that the former PBL students felt significantly more improved than the traditional students in their design-related abilities and some of their teamwork abilities evaluated by the survey.
\end{abstract}

\section{Introduction}

The Electrical and Computer Engineering (ECE) Department of the University of British Columbia offered a traditional lecture and laboratory-based engineering program for many years. Motivated in part by the success of Problem Based Learning in Medicine at MacMaster University in Ontario in the 60's, and its application in Engineering at Denmark's Aalborg University in 1974 [1,2], the ECE Department decided to develop and introduce a new optional second year ECE program called the Project Integrated Program (PIP) in 1999. The purpose of this paper is to describe the program and some aspects of its evaluation to date.

The PIP was conceived as a replacement for all of the Traditional second year ECE courses since all ECE students take the common second year before taking the specialized Electrical Option or the Computer Option courses. However, the PIP retained the courses offered to our students by other departments (the courses in mathematics, computer science and technical communications). The PIP has three major differences from the traditional program. Firstly, four somewhat open-ended design projects which embody all areas of the course background are carried out throughout the year, secondly, the required curriculum content is integrated and delivered just in time for each project, and finally, the students work in teams to carry out the projects. Two questions arose when the program was introduced. Is there evidence that students' ability to apply knowledge and skills in design projects is improved, and is there evidence that teamwork skills are improved.

The following sections describe how the program is structured, how students are assessed, and the results of student surveys relevant to the above issues.

\section{The PIP Methodology}

Since the PIP program ran in parallel with a Traditional second year program, the curriculum content for the two programs was required to match at the end of the second year. While the Traditional program had nine courses in two terms (2 circuit analysis courses, 1 electronic circuits course 1 digital logic design course, 1 introduction to microcomputers course, 1 engineering electromagnetics coutse, 2 laboratory courses and 1 group project course) the PIP program had just 2 integrated courses - one per term. The order in which material was covered in the PIP did not match the Traditional program.

Typically in the PIP, the Module 1 project involved the development of a computer-based data acquisition system requiring the design of a power supply, an operational amplifier circuit, a lab computer containing an analog interface, and a Matlab ${ }^{\mathrm{TM}}$ display of the sensed signals. The second project in Term 1 involved some form of signal detection, processing with display on a 2 line by 24 character LCD display, all carried out by digital logic implemented in an Altera $^{\mathrm{TM}}$ FPGA configured using VHDL. The third module involved electrostatics (employed in the coin detector in the jukebox shown in Figure 1) and a 
microprocessor programmed in assembly language, and the fourth project involved some magnetostatics, such as a coil sensing system in a self-contained DC motor powered car controlled by a C language program.

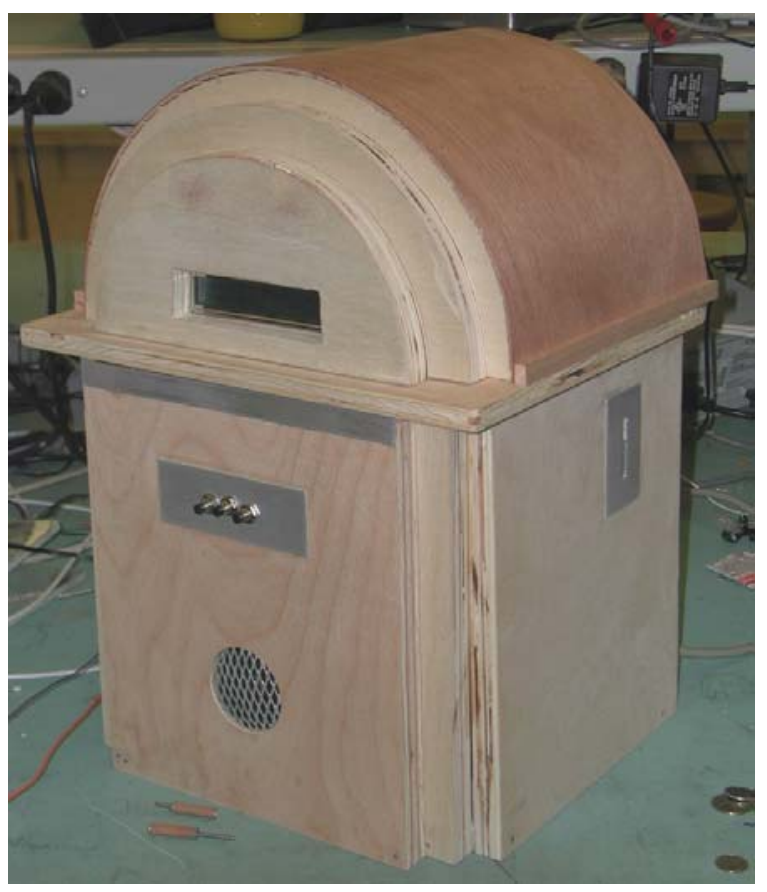

\section{Figure 1. Example of a module 3 project: microprocessor-based jukebox}

In the PIP, students working in teams of 4-6 carried out two design projects per 13 week term. The term was thus divided into two Modules - one per project.

The student projects drove the lecture sequence. The PIP lectures were delivered in one-week blocks, with 5 lectures on Monday to Wednesday (see Table 1). On Thursday and Friday the students in each group met teaching assistants (TA's) and the instructor for that week in a small group meeting room. In the meeting room a student was selected to work through one of the assigned textbook problems with the assistance of fellow students and the staff. The selected student received a grade based on his preparation. Students also discussed their project progress in the meeting rooms. The weekly meeting room grades contributed $10 \%$ to the overall student marks.

The following Monday, students carried out a weekly quiz to allow them to assess their progress in a fairly traditional way. The quiz grades contributed to $20 \%$ of the student's overall grade for the term. To summarize the academic aspect of each week, the first 3 days were dedicated to lectures $(\mathrm{M}, \mathrm{T}, \mathrm{W})$, and the remaining four days were devoted to reviewing, working out, and discussing textbook problems, and reading ahead for the next week.

Table 1. Weekly ECE activity sequence

\begin{tabular}{|c|c|c|}
\hline $\mathbf{M} / \mathbf{T u}$ /W & $\mathbf{T h} / \mathbf{F}$ & Sa/Su \\
\hline Previous & Current week's & Students study \\
week's quiz & Meeting Room & for current \\
(Monday) & Session (3- & week's quiz \\
followed by & hr/group) with & and do next \\
current week's & Instructor and & week's reading \\
5 lectures & TA's, Misc. & and example \\
& Presentations & problems \\
& in 2-hr/class & \\
& & \\
\hline \multicolumn{2}{|c|}{ 6 hours of supervised project time } & \\
\hline \multicolumn{2}{|c|}{} \\
\hline
\end{tabular}

At the end of each 6.5 week Module, the students received a formal examination. The two examinations in the term comprised $30 \%$ of the overall term grade. In total, the "academic" portion of the grades comprised $60 \%$ of the total student grade for the term.

In addition to the normal lecture sequence, on Thursdays and Fridays, lecture times were available for various topics such as working in teams, fitting experimental data for calibration and other purposes, use of the library and web resources, electrical safety, capabilities and use of the machine shop, practical data communications, and end-of-module group presentations. Although not examined in the traditional sense, these topics were added to assist the projects.

Projects were assessed by a team of instructors and teaching assistants. The system and subsystem performance were first demonstrated by the students and the various aspects of the design approach were explained. The contributions of the various members of the team were also explained. Then the individual students were interviewed to assess their level of understanding of what they did and the other aspects of the system that they did not work on. The students then completed an online peer review questionnaire. On the basis of the demonstration, the interviews, the peer reviews, and the experience of the laboratory instructor and the laboratory teaching assistants, a mark was assigned to the group (which contributed to $15 \%$ of the grade for each student in the group for the term), and to each student (representing 10\% of the 
grade for the term). In addition each student was responsible for contributing to a final report (and an earlier conceptual design document) representing up to $10 \%$ of the course, and presentations worth up to $5 \%$ of the course. In total, the project component comprised $40 \%$ of the course.

\section{Evaluation}

Although many surveys of the PIP students have been carried out, and minor improvements have been made, the most relevant measurements to this paper came as a result of a survey of third and fourth year students. In ECE, students took a variety of third and fourth year courses depending on their program and their elective selection. Therefore they were surveyed as a single group of post-second-year students. The request for the students to complete the online survey was made by the Department Head.

In the survey, the students were asked a number of categorization questions to identify which program they were in (Electrical Engineering or the Computer Engineering), which options they had taken (Mathematics, Software), whether they had taken the PIP or the Traditional option etc. In the survey there were six statements requiring a response specifically related to design and four statements specifically related to teamwork skills. Each statement took the following form:

"Over the course of my ECE education at UBC, I would rate the improvement in my ability to ..."

The remaining portions of the statements are given in Table 2.

There were five possible responses to the statements (very high, high, moderate, low, and very low). A weight was assigned to the responses ranging from 1 (very high) to 5 (very low). These Likertscaled responses were tabulated and statistically tested for significance. Using the students' responses to the PIP or Traditional categorization question, the students were separated into two groups.

Due to interval nature of the Likert scale, a nonparametric two sample Mann-Whitney test was selected to assess significance of the difference between the PIP and Traditional groups. The 2-tailed significance of the SPSS ${ }^{\mathrm{TM}}$-calculated $\mathrm{z}$-statistic for each question is reported in Table 3.

It can be seen that for all the Design questions, the hypothesis that the responses from the PIP and the Traditional groups can be rejected at the 0.05 level. Thus there are significant differences between the PIP and Traditional groups at the .05 level. Since the differences in mean rank in the table are positive, PIP group rankings are lower on all of the design related questions. The fact that they are lower is a result of the choice of a numerical value of " 1 " being assigned to a "very high" response to survey questions.

Thus the PIP students felt significantly more improved in the various design competencies tested, than the Traditional students did.

\section{Table 2. Questionnaire statements}

\begin{tabular}{|c|c|}
\hline ID & Statement \\
\hline Design1 & $\begin{array}{l}\ldots \text { meet project design objectives or } \\
\text { functional specifications as ... }\end{array}$ \\
\hline Design2 & $\begin{array}{l}\text {...see the overall ("Big") picture of a } \\
\text { design as ... }\end{array}$ \\
\hline Design3 & $\begin{array}{l}\text {...break a large complex task into more } \\
\text { manageable sub-tasks as ... }\end{array}$ \\
\hline Design4 & $\begin{array}{l}\text {...foresee potential design problems at } \\
\text { the beginning of a project as ... }\end{array}$ \\
\hline Design5 & $\begin{array}{l}\text {...brainstorm with others to come up } \\
\text { with new ideas as ... }\end{array}$ \\
\hline Design6 & $\begin{array}{l}\text {...be creative and practical in my } \\
\text { solutions to problems as ... }\end{array}$ \\
\hline Team1 & $\begin{array}{l}\text {...function as a productive member of a } \\
\text { team as... }\end{array}$ \\
\hline Team2 & $\begin{array}{l}. . \text { give and receive constructive criticism } \\
\text { as ... }\end{array}$ \\
\hline Team3 & $\begin{array}{l}\text {...take charge of and complete assigned } \\
\text { tasks as... }\end{array}$ \\
\hline Team4 & $\begin{array}{l}\text {...understand and integrate the work of } \\
\text { other team members into the overall } \\
\text { design as ... }\end{array}$ \\
\hline
\end{tabular}

In the Team questions, only the first two questions showed significant differences between the two 
groups. The last Team question was close to significance, but the third question was not. From examining the mean responses of the groups in the third question, it was clear that both groups felt reasonably, and similarly improved at "taking charge of and completing assigned tasks".

Table 3. Analysis of student responses

\begin{tabular}{|c|c|c|c|}
\hline Question & $\begin{array}{c}\text { Difference } \\
\text { in Mean } \\
\text { Rank } \\
\text { (Trad-PIP) }\end{array}$ & $\mathbf{Z}$ & $\begin{array}{c}\text { 2-tailed } \\
\text { significance }\end{array}$ \\
\hline Design1 & 16.8 & -2.547 & .011 \\
\hline Design2 & 15.3 & -2.296 & .022 \\
\hline Design3 & 13.6 & -.2044 & .041 \\
\hline Design4 & 13.1 & -1.966 & .049 \\
\hline Design5 & 20.9 & -3.160 & .002 \\
\hline Design6 & 13.5 & -2.016 & .044 \\
\hline Team1 & 17.1 & -2.648 & .008 \\
\hline Team 2 & 14.3 & -2.141 & .032 \\
\hline Team3 & 8.43 & -1.262 & $.207>.05$ \\
\hline Team4 & 12.1 & -1.837 & $.066>.05$ \\
\hline
\end{tabular}

\section{Discussion}

Not all of the questions related to PIP have been addressed here. The issues examined are related to the more difficult to quantify skills not easily measured by tests and examinations. It is clear from the many surveys of PIP students that the students like the program and realize its benefits even though it is clear that it requires more effort.

It was seen as necessary in PIP that the curriculum match the Traditional curriculum to the greatest possible extent. That does not mean that the lecture contents match. In fact the students received about $30 \%$ fewer lectures. However the reading assignments come closer to covering the curriculum.

Although it may appear that students could forget the material after the first module quiz, and thereby reduce their retention, in fact, the need for much of the material continues throughout the academic year. So for example, electric circuit concepts, and electronic circuits are continuously drawn upon in subsequent modules. It is also true that unresolved problems in earlier modules (e.g. noise problems) are later explained by insight obtained in a subsequent Module (electrostatic shielding).

One of the major differences between the PIP program and any previous engineering PBL programs [3] of which we are aware, is that the PIP projects largely drive the whole of the second year ECE curriculum content. The advantage to this is that students are very focused on the lecture content as it provides a framework for the knowledge that they require. The disadvantage is that the students become much less tolerant of knowledge that might be "good for you someday". The selection of suitable projects then becomes quite important.

\section{Conclusions}

The results of the reported evaluation indicate that compared to the traditional students, PIP students do feel that their design skills and some of their teamwork skills are more improved.

\section{References}

[1] F. Kiersdam and S Enemark, The Aalbog ExperimentProject Innovation in University, Aalborg University Press, 1994.

[2] F. K. Fink, "Integration of Engineering Practice into Curriculum - 25 Years of Experience with Problem Based Learning", Frontiers in Education Conf. (FIE'99), vol. 1, pp. 11A2-7-11A-12, Nov. 1999.

[3] J. E. Mills and D. F. Treagust, "Engineering Education - Is Problem-Based or Project-Based Learning the Answer?", Australasian J. of Engineering Education, http://www.aaee.com.au/journal $/ 2003 / \mathrm{mills}$ treagust0 3.pdf, pp. 1-16, AAEE, 2003.

\section{Acknowledgements}

The authors acknowledge the kind assistance of the staff of Aalborg University, the PBL discussions with Dr. KD Shrivastava, startup funding from Dr. M. Isaacson, Dean, Faculty of APSC and the UBC TLEF, and the support of the NSERC Design Engineering Chairs Program. 